\title{
RISK OF EXPOSURE TO ACRYLAMIDE
}

\author{
Milena Bušová1, Vladimír Bencko1, Katarína Veszelits Laktičová2, Ivana Holcátová1 Mária Vargová2 \\ IInstitute of Hygiene and Epidemiology, First Faculty of Medicine, Charles University and General University Hospital in Prague, Prague, \\ Czech Republic \\ ${ }^{2}$ Department of the Environment, Veterinary Legislation and Economy, University of Veterinary Medicine and Pharmacy, Košice, Slovak Republic
}

\begin{abstract}
SUMMARY
Objectives: Acrylamide is a toxic compound that can be found it both occupational and non-occupational environments. This study focuses on its sources and health effects of its exposure.

Methods: Adverse effects of acrylamide, especially carcinogenic, genotoxic, and teratogenic were reported in many studies conducted on animals. Neurotoxicity was reported in workers exposed to acrylamide in the occupational environment. Another important source of populations' exposure to acrylamide is their nutrition.

Results: This study focuses on humans' exposure to acrylamide from various sources and its harmful effects on their health.

Conclusions: Dietary intake of acrylamide, as well as occupational exposure, cigarette smoking, cosmetics usage and other environmental sources could have a significant effect on human health.
\end{abstract}

Key words: acrylamide, polyacrylamide, neurotoxin, carcinogen, occupational exposure

Address for correspondence: M. Bušová, Institute of Hygiene and Epidemiology, First Faculty of Medicine, Charles University in Prague, Studničkova 7, 12800 Praha 2, Czech Republic. E-mail: milena.busova@lf1.cuni.cz

https://doi.org/10.21101/cejph.a6177

\section{INTRODUCTION}

Acrylamide (ACR) is well-known chemical compound, widely used in many countries. It has been largely produced in Japan, the USA and in Europe from 1990 (1). In 1995, the total production in the European Union was between 80,000 and 100,000 tons. In 2008, in the United States the production of acrylamide was about 141,000 tons (2-4). Most of this amount is used for the production of polyacrylamide made for different purposes (1).

ACR is often used in constructions as a waterproof material to seal and ground foundations of dams and tunnels, in paper production, as an additive into cosmetics, in laboratories for electrophoresis, and in the textile industry for dye dispersion (3, 5-7). Polyacrylamide is non-toxic, but its monomer acrylamide has some toxic effects and should only be present as a residue of polyacrylamide. ACR monomer can be released to the environment during production and industrial use of polyacrylamides (4).

Acrylamide is a polar compound, with a high mobility in soil and water. It does not accumulate in the soil, from which it can be rapidly eliminated. Polyacrylamide is biodegradable (8). Presence of ACR in the environment is associated with the degradation of polyacrylamide, e.g. degradation of building materials etc. Environmental conditions such as heat or light, or even outdoor exposures except $\mathrm{pH}$, promote depolymerization of polyacrylamide to acrylamide (9). Because of the potential risk of environmental contamination, the usage of acrylamide in cosmetics, in drinking water preparation and in packaging materials for foodstuffs is regulated $(2-4,10)$. ACR is also used as flocculant during cleaning processes of wastewater treatment and preparation of drinking water $(11,12)$. The residue of its monomeric form can be present as contaminant in drinking water. Moreover, ACR was identified in some foodstuffs cooked at high temperature, above $120^{\circ} \mathrm{C}$ as a result of Maillard reaction $(10,13,14)$. The concentration of acrylamide in various types of food depends on the composition of the food, cooking method, heating temperature, and the length of the heating process (baking, frying, and grilling) (4). ACR has also been identified in food products dedicated to farm animals prepared in similar conditions, with high-temperature technology and drying (15), presence of it is expected in various feed for livestock (15).

\section{Risk for Human Health}

ACR is toxic and potentially danger chemical compound. Neurotoxicological effects of ACR were reported by many authors (16).

In 1994, the International Agency for Research on Cancer (IARC) classified acrylamide as probably carcinogenic to humans, group 2A (17). Since 1980 a number of animal studies have also showed its genotoxicity and teratogenicity (16). In laboratory, animals such as rodents, Guinea pigs, rabbits, cats, and dogs were daily exposed to ACR $(0.5-50 \mathrm{mg} / \mathrm{kg}$ per day), and the neurological effects occurring in them were similar to the ones observed in humans (18).

Other studies have shown that exposure to ACR increases the incidence of cancer in rats at an acrylamide dose of 1-2 mg. $\mathrm{kg}^{-1}$ of body weight (b.w.) per day (5). Friedman reported three major adverse effects in animals: neurotoxicity, teratogenicity and carcinogenicity (5).

In addition to neurotoxic, genotoxic, carcinogenic, mutagenic, and teratogenic effects, the damage on reproductive functions have been proved (19). 
ACR is a biological alkylating agent that binds to DNA as well as to essential proteins and enzymes, causing chromosomal and therefore genetic mutations in both, somatic and germ cells. Worldwide, the effects of ACR have been intensively studied for a long period, not only in relation to the potentially harmful effect in occupationally exposed workers but also in relation to its occurrence in daily life.

Due to its harmful effects and the chronic dietary exposure of the population to ACR, limiting the usage and monitoring of levels ACR in foodstuffs as well as its effects on human health ranked amongst the priorities of authorities such as the World Health Organization (WHO), the European Food Safety Authority (EFSA), the Food Agriculture Organization (FAO), and others. It is therefore important to identify all sources of exposure to ACR and to establish a safe daily exposure to ACR for humans.

\section{MATERIALS AND METHODS}

The main sources of human exposure to ACR are their working environment, diet, smoking habits, and other sources.

\section{Sources of Exposure in Occupational Settings}

There are many reported cases of neurological disorders among workers who were exposed to acrylamide containing grouting agents and other materials (20).

ACR entry route in exposed workers is through dermal absorption, inhalation of dry ACR monomer or aerosol in the manufacturing, and applications of acrylamide or polyacrylamide preparation. Workers were occupationally exposed during application e.g. grouting agents to cracks in concrete to protect and prevent water seeping into floors, roofs, and walls (20). Two cases of neurological symptoms, reduced sensory functions and strength, weakness in the legs, and skin peeling after occupational exposure to grouting agent were reported by Kim et al. (20). Workplace exposure to acrylamide through dermal contact and inhalation of dust or vapours can lead to the neural toxicity and dermatitis (20). Harmful effects on workers were reported by other authors (21). The American Environmental Protection Agency (EPA) issued a warning in 1987 regarding the hazards of airborne exposure and dermal contact with acrylamide during chemical grouting work. The European Union (EU) has also recommended limiting the use of these agents. According to legislation in the Czech Republic (CR) and EU Directive No. 2017/2398 the current limit of exposure to acrylamide in the occupational environment is $0.1 \mathrm{mg} \cdot \mathrm{m}^{-3}$ in the working atmosphere (22).

\section{Sources of Exposure from Food}

A significant source of non-professional exposure for population to ACR is heat-treated food. Tareke et al. reported relatively high levels of acrylamide in heated commercial foodstuffs and in foods cooked at high temperature, especially in carbohydrate rich foods $(23,24)$. Thus he pointed to a significant source of exposure of population to the ACR from heat treated foods. ACR is included in the list of process contaminants that occur in foodstuffs (carbohydrates rich food) as a result of the reaction between main components of food (carbohydrates and proteins) by the heating treatment known as Maillard reaction $(10,15,17)$. These widely publicized findings led to worldwide studies on determination of acrylamide levels in food from the naturally occurring substances (5). From 2002, many authors published their results of ACR analysis in various types of foodstuffs prepared under different technological conditions (25). The highest amount of ACR is formed by Maillard reaction in raw products with high content of asparagine and glucose when heated to $180^{\circ} \mathrm{C}(5)$. However, no acrylamide was found in unheated or boiled foods (24).

\section{Sources of Exposure from Drinking Water}

In some cases, the general public can be exposed to ACR from drinking water, especially in the case of treatment of public drinking water sources using polyacrylamide as a flocculant (26). The burden on the population drinking water from public sources using polyacrylamide as a flocculant for treatment is approximately $0.0036 \mu \mathrm{g} \cdot \mathrm{kg}^{-1}$ b.w. per day but can be as high as $0.11 \mu \mathrm{g} . \mathrm{kg}^{-1}$ b.w. per day (27). In the Czech Republic, the amount of ACR is limited to $0.1 \mu \mathrm{g} . \mathrm{L}^{-1}$ in water. This limit is valid not only in the CR but, also in the European Union (12). Using a comparison of the food consumption and drinking water, the authors of many studies predicted that the ingestion of acrylamide with food may be much higher than with water (28).

\section{Sources of Exposure from Smoking Cigarettes}

Cigarette smoke contains a large number of organic toxic substances including carcinogens.

Tobacco smoke is another important source of exposure to ACR in smokers in addition to dietary intake (29). There are, however, only a few studies about the content of ACR in tobacco smoke. Significant differences in the acrylamide content in cigarettes available on the markets in different countries were noted. There are three possible mechanisms of acrylamide formation in tobacco: the reversible reaction of ammonia with acrylic acid, the reaction of asparagine with reducing sugars and, the acrylamide formation from acrolein (29). All these chemical reactions are possible mechanisms of acrylamide formation in food, too. The presence of all ACR precursors is indicated in tobacco and in tobacco smoke as well (30). The levels of acrylamide in raw tobacco are lower than in cigarette smoke. Some authors confirmed that acrylamide is created in the process of cigarette smoking. According to the Mojska et al., the average content of acrylamide is $679.3 \mathrm{ng}$ per cigarette with a range of 455.0-822.5 ng per cigarette. The estimated average exposure to acrylamide from tobacco smoke in adult smokers in Poland is $0.17 \mu \mathrm{g} . \mathrm{kg}^{-1}$ b.w. per day (29). A study by Madle et al. reported an average content $1.2 \mu \mathrm{g}$ of acrylamide per one cigarette (1). The authors reported that smoking on average 20 cigarettes per day correlates to the body being exposed to acrylamide intake of $0.5 \mu \mathrm{g} . \mathrm{kg}^{-1}$ b.w. per day (29).

From some preliminary studies it seems that ACR has adverse effect to thyroid. From the beginning of the nineties we can find the increasing incidence of cancer of thyroid in many countries especially those from well developed world. So, the cohort study was established whether the observed excess of thyroid cancer is associated with the exposure to acrylamide. It is not clear to what extent the amount of acrylamide present in cigarette smoke and/or 
food contributes to the aetiology of human cancers (5). According to the EFSA statement, acrylamide is present in tobacco smoke, which is, therefore, a non-dietary source of exposure for both smokers and non-smokers (through passive smoking). For smokers, tobacco smoking is a more prominent source of acrylamide exposure than food (7).

\section{Sources of Exposure from Cosmetics}

Prohibited substances in cosmetics refer to substances which must not be among the raw ingredients of cosmetic products. These substances can be absorbed mostly through the skin, as well as via the lung and the gastrointestinal tract. The use of acrylamide in cosmetic products represents a considerably significant burden on the population from their usage. The originally authorized amount of $100 \mathrm{mg} \cdot \mathrm{kg}^{-1}$ cosmetic product was limited to a level $<0.5 \mathrm{mg} . \mathrm{kg}^{-1}$ due to ACR toxicity. Daily exposure from cosmetics decreased to $0.7 \mu \mathrm{g} . \mathrm{kg}^{-1}$ b.w. per day (1).

\section{RESULTS AND DISCUSSION}

Due to its toxicity, negative impact on human reproduction system and long term chronic burden of population, ACR is monitored in relation to damage to human health.

Acrylamide and its metabolite, glycidamide, are both genotoxic and carcinogenic compounds. Tolerable daily intake (TDI) due to its genotoxicity, and mutagenicity is not established. Since any level of exposure to a genotoxic substance could potentially damage DNA and lead to cancer, EFSA scientists conclude that they cannot set a tolerable daily intake of acrylamide in food.

\section{Risk to the Population}

The margin exposure limit (MOE) of $0.2 \mathrm{mg} \cdot \mathrm{kg}^{-1}$ b.w. per day, calculated from the no-observed-adverse-effect level (NOAEL) for the most sensitive noncarcinogenic effects, morphological changes in nerves, and detected by electron microscopy in rats, therefore, remains unchanged. EFSA experts concluded that for these effects, current levels of dietary exposure are not a health concern, although for toddlers and children with high dietary exposure the MOE is close to the values that might be of concern (7). The issue of acrylamide and its effects on human health is being dealt with by world institutions and authorities such as the WHO, the FAO, the Joint Institute for Food Safety and Applied Nutrition (JIFSAN), and more. The results and new pieces of knowledge are updated and published. These data are important for the estimation of risk for the population as well as for establishing safe levels for foodstuffs or changes in their preparation methods. EFSA experts stated that ACR in food is a processed contaminant (7). Based on the findings of the calorie content of the U.S. diet, the risk assessment suggests that up to $40 \%$ of all foods contain acrylamide (5). Friedman published that children may be more at risk than adults since the amount of ACR consumed per kilogram of body weight is more important (5).

The epidemiologic evaluations of cancer risk in workers, which were occupationally exposed to ACR, were published from 1980. Two cohort studies of workers professionally exposed in the industry were reported, but no consistent results of ACR exposure and cancer incidence were found (31). In another study, laboratory workers were exposed to airborne acrylamide used in the preparation of polyacrylamide gels for laboratory analysis. In this study, the working air concentrations for the calculated 8-hour time weighted average of exposure were below of current occupational exposure limit as a result of short-time exposure to this compound (32). On the other hand, the workers in whole shift exposure were exposed to a long-term load of ACR. ACR metabolite, glycidamide, alkylates the proteins and can form adducts with haemoglobin. Detoxification of the organism is possible due to glutathione, by conjugation with glycidamide, and excretion as a mercapturic acid to urine. This metabolite can be used as marker of human exposure to ACR (5). Some authors reported that acrylamide is frequently used in Korea for grouting works. It does not appear to be of significant interest in the prevention of its use or its effects on worker's health (21). Determination of the haemoglobin adducts is useful as it is a significant marker for risk assessment in human exposure to ACR (33). Therefore, it is useful to monitor human exposure to acrylamide from dermal contact, diet, drinking water, smoking, and the workplace.

\section{CONCLUSIONS}

Dietary intake of ACR in developed countries due to the consumption of favourite foodstuffs, drinking water, and cosmetics usage is not negligible. A combination with occupational exposure could have a significant effect on the human health. The risk is much higher in smokers. The most vulnerable are smokers who are professionally exposed to ACR. This situation can be more complicated when the dietary intake of ACR from processed foodstuffs is combined with the other potentially toxic compounds, contaminants in food such as mycotoxins, residuals of pesticides, or some additives, naturally occurring compounds as well as some groups of drugs used for treatment.

\section{Acknowledgement}

This work was supported by the Charles University in Prague, First Faculty of Medicine by grant PROGRES Q25/LF1.

\section{Conflict of Interests}

None declared

\section{REFERENCES}

1. Madle S, Broschinski L, Mosbach-Schulz O, Schöning G, Schulte A. On current risk assessment of acrylamide in food. BundesgesundheitsblattGesundheitsforschung-Gesundheitsschutz. 2003;46(5):405-15.

2. IARC working group on the evaluation of carcinogenic risks to humans: some industrial chemicals. Lyon, 15-22 February 1994. IARC Monogr Eval Carcinog Risks Hum. 1994;60:1-560.

3. National Industrial Chemicals Notification and Assessment Scheme (Australia). Acrylamide. Sydney: NICNAS; 2002.

4. Toxicological profile for acrylamide. Atlanta: Agency for Toxic Substances and Disease Registry; 2012.

5. Friedman M. Chemistry, biochemistry, and safety of acrylamide. A review. J Agric Food Chem. 2003 Jul 30;51(16):4504-26.

6. Papoušek R, Nováková P, Marková E, Barták, P. Analysis of acrylamide by GC-MC method. Chem Listy. 2013;107(3):255-60. (In Czech.) 
7. EFSA Panel on Contaminants in the Food Chain (CONTAM). Scientific opininon on acrylamide in food. EFSA J [Internet]. 2015 Jun [cited $2020 \mathrm{Jul}$ 15];13(6):4104. Available from: https://doi.org/10.2903/j. efsa.2015.4104.

8. Smith EA, Prues SL, Oehme FW. Environmental degradation of acrylamides II. Effects of environmental (outdoor) exposure. Ecotoxicol Environ Saf. 1997;37(1):76-91.

9. Smith EA, Pruen SL, Oehme FW. Environmental degradation of polyacrylamides. I. Effects of artificial environmental conditions: temperature, light and pH. Ecotoxicol Environ Saf. 1996;35(2):121-35.

10. Ciesarová Z. Minimizing acrylamide in food. Chem Listy. 2005;99(7):48391. (In Slovak.)

11. Pivokonský M, Bubáková P, Pivokonská L, Knesl B. Suspension formation in water treatment: theory and practice. Líbeznice: Medim; 2011. (In Czech)

12. Decree No $70 / 2018$ amending Decree No 252/2004 laying down health requirements for drinking and hot water and the frequency and scope of drinking water control, as amended. Sbírka zákonů ČR. 2018 Apr 27;Pt 35:946-72. (In Czech.)

13. Yaylayan VA, Wnorowski A, Locas CP. Why asparagine needs carbohydrates to generate acrylamide. J Agric Food Chem. 2003;51(6):1753-7.

14. Gökmen V, Palazoğlu TK. Acrylamide formation in foods during thermal processing with a focus on frying. Food Bioproc Tech. 2008;1(1):35-42.

15. Kurtz DM, Glascoe R, Caviness G, Locklear J, Whiteside T, Ward T, et al. Acrylamide production in autoclaved rodent feed. J Am Assoc Lab Anim Sci. 2018 Oct 25;57(6):703-11.

16. LoPachin RM, Ross JF, Lehning EJ. Nerve terminals as the primary site of acrylamide action: a hypothesis. Neurotoxicology. 2002 May;23(1):43-59.

17. Acrylamide. IARC Monogr Eval Carcinog Risks Hum. 1994;60:389-433.

18. Johnson KA, Gorzinski SJ, Bodner KM, Campbell RA, Wolf CH, Friedman MA, et al. Chronic toxicity and oncogenicity study on acrylamide incorporated in the drinking water of Fischer 344 rats. Toxicol Appl Pharmacol. 1986 Sep 15;85(2):154-68.

19. Shipp A, Lawrence G, Gentry R, McDonald T, Bartow H, Bounds J, et al. Acrylamide: review of toxicity data and dose-response analyses for cancer and noncancer effects. Crit Rev Toxicol. 2006;36(6-7):481-608.

20. Kim H, Lee SG, Rhie J. Dermal and neural toxicity caused by acrylamide exposure in two Korean grouting workers: a case report. Ann Occup Environ Med. 2017 Oct 9;29:50. doi: 10.1186/s40557-017-0207-7.

21. Hagmar L, Törnqvist M, Nordander C, Rosén I, Bruze M, Kautiainen A, et al. Health effects of occupational exposure to acrylamide using hemoglobin adducts as biomarkers of internal dose. Scand J Work Environ Health. 2001;27(4):219-26.

22. Directive (EU) $2017 / 2398$ of the European Parliament and of the Council of 12 December 2017 amending Directive 2004/37/EC on the protection of workers from the risks related to exposure to carcinogens or mutagens at work. Offic J Eur Union. 2017;60(L 345):87-95.

23. Tareke E, Rydberg P, Karlsson P, Eriksson S, Toernqvist M. Acrylamide: a cooking carcinogen? Chem Res Toxicol. 2000;13(6):517-22.

24. Tareke E, Rydberg P, Karlsson P, Eriksson S, Tornqvist M. Analysis of acrylamide, a carcinogen formed in heated foodstuffs. J Agric Food Chem. 2002;50(17):4998-5006.

25. Cwiková O. Toxic effects of acrylamide and its occurrence in food. Chem Listy. 2014;108(3):205-10. (In Czech.)

26. Backe WJ, Yingling V, Johnson T. The determination of acrylamide in environmental and drinking waters by large-volume injection - hydrophilic-interaction liquid chromatography and tandem mass spectrometry. J Chromatogr A. 2014 Mar 21;1334:72-8.

27. Hansen BG, Munn SJ, Luotamo M, Musset C, de Bruijn J, Pakalin S, et al., editors. Acrylamide: risk assessment. European Union risk assessment report, vol. 24. Luxembourg: Office for Official Publications of the European Communities; 2002.

28. Dearfield KL, Douglas GR, Ehling UH, Moore MM, Sega GA, Brusick DJ. Acrylamide: a review of its genotoxicity and an assessment of heritable genetic risk. Mutat Res. 1995;330(1-2):71-99.

29. Mojska H, Gielecińska I, Cendrowski A. Acrylamide content in cigarette mainstream smoke and estimation of exposure to acrylamide from tobacco smoke in Poland. Ann Agric Environ Med. 2016;23(3):456-61.

30. Moldoveanu SC, Gerardi AR. Acrylamide analysis in tobacco, alternative tobacco products, and cigarette smoke. J Chromatogr Sci. 2011;49(3):234-42.

31. Rice JM. The carcinogenity of acrylamide. Mutat Res. 2005 Feb 7; 580(1-2):3-20.

32. Pantusa VP, Stock TH, Morandi MT, Harrist RB, Afshar M. Inhalation exposures to acrylamide in biomedical laboratories. AIHA J (Fairfax, Va). 2002 Jul-Aug;63(4):468-73.

33. Springer DL, Bull RJ, Goheen SC, Sylvester DM, Edmonds CG. Electrospray ionization mass spectrometric characterization of acrylamide adducts to hemoglobin. J Toxicol Environ Health. 1993;40(2-3):161-76.

Received March 14, 2020 Accepted in revised form July 15, 2020 